\title{
American Attitudes in Context: Posthumous Sperm Retrieval and Reproduction
}

\author{
Jason D Hans* and Erin L Yelland
}

Department of Family Sciences, University of Kentucky, USA

\begin{abstract}
Although still exceedingly uncommon, evidence suggests that the prevalence of posthumous sperm retrieval requests for reproductive purposes has increased in recent years within the United States. These requests raise complex issues that pose challenges for physicians, legal scholars, and bioethicists. This study is among the first to examine the general population's attitudes toward posthumous sperm retrieval and, more generally, toward posthumous reproduction. Specifically, the effects of five contextual circumstances-marital status, parental status, wishes of the deceased's parents, context of death, and the wishes of the deceased-on attitudes toward posthumous sperm retrieval for the purpose of cryopreservation and reproduction were examined using a multiple segment factorial vignette with a probability sample of 846 households in the United States. Marital status, disposition of the deceased's parents, and the deceased's wishes affected attitudes in predictable directions, parental status and cause of death had little bearing on attitudes, and respondent religiosity was negatively related to the perceived acceptability of posthumous sperm retrieval as well as medical professional's obligation to perform the procedure.
\end{abstract}

Keywords: Attitudes; Gamete cryopreservation; Posthumous harvesting; Posthumous reproduction; Sperm retrieval

\section{Introduction}

Gamete cryopreservation is typically performed with the donor's knowledge and consent as insurance against an impending experience that may lead to infertility, but retrieving (sometimes referred to as harvesting) gametes from incapacitated or deceased individuals without the donor's consent also occurs. For example, cases have been documented in which spouses, intimate partners, and parents have requested that gametes be retrieved from patients in vegetative states, comas, or who had been diagnosed as brain dead $[1,2]$. Requests may also come from surviving partners or family members for postmortem retrieval from a cadaver in the hours following an unexpected death, especially when the deceased individual or couple's reproductive plans had not reached fruition prior to an untimely death [3].

Posthumous sperm retrieval for the purpose of procreation was first reported by Rothman in 1980 [4], and the first successful pregnancy using sperm retrieved from a cadaver occurred in 1998 followed by the subsequent birth in 1999 [5]. Although retrieval, cryopreservation, and subsequent conception are straight forward procedures when the deceased is male, the procedures are medically and legally more complex when the deceased is female (e.g., a surrogate mother is needed) and a conception using gametes posthumously retrieved from a female has not yet been reported.

Some countries have established laws banning or regulating posthumous gamete retrieval and conception, but the practice is not prohibited by law in most countries, including the United States. Although permissible in most locations, the ethical and legal issues associated with posthumous reproduction are among the "most challenging, difficult and sensitive one is likely to encounter in any field of medicine" [6]. For example, one hospital ethics committee tasked with providing advice to physicians about the ethics of posthumously retrieving sperm in a particular case focused instead on liability concerns, apparently unable to provide guidance on the ethics of the procedure itself [2]. That said, some hospitals have developed guidelines for postmortem sperm retrieval, such as those established by Cornell University and utilized by several New York hospitals [7]; hereafter referred to as the Cornell guidelines].
The Cornell guidelines emphasize four areas of consideration: (a) issues of consent, (b) medical contraindications, (c) resource availability, and (d) a waiting period prior to conception. More specifically, the guidelines stipulate that consent of the deceased must be presumed, consent for retrieval can only be provided by the deceased's wife, the death must have been sudden and for reasons not due to a communicable disease or one known to affect sperm viability, retrieval must take place within 24 hours of death, cryopreservation must be available locally, the wife must wait a year prior to using the sperm, and the sperm should be screened for communicable diseases. A retrospective review of 22 cases where postmortem sperm retrieval was requested between 1994 and 2002 found that 18 were not candidates for retrieval based on the Cornell guidelines, and among the four cases where retrieval was performed, only one wife had attempted pregnancy using the cryopreserved sperm [8].

Although bioethicists and legal scholars have written extensively about what should or should not be permitted or considered in the context of posthumous gamete retrieval, only a few studies have examined perceptions among the general population. One such study focused on posthumous donation of female gametes to unknown recipients and found that, among a representative sample of Utah residents, $57 \%$ of respondents "were comfortable donating their own or partner's oocytes for fertilization and transfer of the resulting embryos to a couple desiring pregnancy" in the event of death [9]. Another study of couples presenting for their first fertility consultation in New York found that $85 \%$ of males and $72 \%$ of females "would permit their spouse to harvest their [own] eggs/sperm for the purpose of conceiving a child

*Corresponding author: Jason D Hans, Department of Family Sciences, 315 Funkhouser Building, University of Kentucky, Lexington, KY 40514, USA, E-mail: jhans@uky.edu

Received February 15, 2013; Accepted May 13, 2013; Published June 07, 2013

Citation: Hans JD, Yelland EL (2013) American Attitudes in Context: Posthumous Sperm Retrieval and Reproduction. J Clinic Res Bioeth S1: 008. doi:10.4172/21559627.S1-008

Copyright: (C) 2013 Hans JD. This is an open-access article distributed under the terms of the Creative Commons Attribution License, which permits unrestricted use, distribution, and reproduction in any medium, provided the original author and source are credited. 
after their death" [10]. An intercouple analysis of these respondents found that $79 \%$ of females and $71 \%$ of males accurately predicted their spouse's response to this question. Another study based on a national probability sample of 2,074 households in the continental United States found that $64 \%$ of males and $55 \%$ of females were comfortable with the prospect of their gametes being used posthumously by a partner if an early death were to occur [11].

Using a probability sample of Kentucky households, Hans [3] administered a more sophisticated true-experiment survey design using a vignette. Specifically, a hypothetical scenario was presented in which posthumous gamete retrieval was requested by a surviving spouse or partner. Several key details in the vignette-sex of the deceased, marital status, relationship length, circumstances of the death, parental status and plans of the couple, wishes of the deceased, and disposition of the deceased's parents-were independently and randomly manipulated across respondents, allowing causal attributions to be made about how contextual circumstances affected attitudes. Overall, the results indicated that context matters when posthumous retrieval of gametes is requested. For example, support for posthumous gamete retrieval ranged from about $80 \%$ among those whose vignette presented a married couple with written consent from the deceased, to less than $20 \%$ among those whose vignette presented a cohabiting couple who had never discussed posthumous retrieval and the deceased's parents were unsupportive of the retrieval request. Also, respondents with more education tended to be more supportive of posthumous gamete retrieval, and respondents who more closely identified with their chosen religion tended to be less supportive of the gamete retrieval request.

The research design employed by Hans [3] uniquely documented the effects of contextual circumstances on attitudes toward posthumous gamete retrieval. However, the generalizability of those findings is limited because they were based on a probability sample of Kentucky households. Given the strength of the true-experiment design for examining attitudes juxtaposed with the sample limitations, the purpose of this study is to examine whether Hans' findings replicate with a larger national sample. Specifically, we examine the effects of five contextual variables on attitudes toward posthumous sperm retrieval for the purpose of procreation: (a) marital status, (b) parental status, (c) wishes of the deceased's parents, (d) context of death, and (e) the deceased's wishes. Prior to describing the design and vignette in greater detail, we briefly explain our rationale for examining each of these variables.

\section{Marital status}

The Cornell guidelines stipulate that only a wife should be able to give permission for posthumous sperm retrieval. Not surprisingly, requests for retrieval are most commonly made by wives [12], and Hans [3] found that attitudes toward both the procedure and physicians' obligation to assist were more favorable when requested by a wife than by a cohabiting partner. However, several cases have arisen where fiancées and cohabiting girlfriends have wanted to reproduce using the sperm of a deceased partner [12,13], and these requests are likely to become more common as the marriage rate declines and age at marriage continues to rise [14], and as cohabitation becomes more common among reproductive-aged couples.

The prevalence of cohabitation among unmarried other-sex partners in the United States increased $18 \%$ over a recent 4 -year period, from 6.4 million in 2007 to 7.6 million in 2011 [15]. As a result, unmarried cohabiting couples now comprise over $11 \%$ of all other-sex couples who live together, and $12.5 \%$ of all children under 1 year of age are living with both biological parents but their parents are unmarried [16]. Moreover, the majority of these cohabiting relationships will end in marriage. The National Survey of Family Growth [17] found that, among cohabiting respondents, more than one-third were engaged or had plans to marry at the time they began cohabiting, and about two-thirds reported better than a 50-50 chance of marriage with their cohabiting partner. Indeed, $60 \%$ of women's first cohabitation experience ends as a result of transitioning into marriage with her cohabitation partner [18]. These numbers indicate that many cohabiting couples have children together without or prior to marriage, and an even larger portion of cohabiters will transition into marriage and have children within marriage in due time. Thus, although unmarried cohabiting partners generally do not have the rights and responsibilities of spouses, it is not unreasonable to presume that many cohabiting couples wish to, and eventually will, procreate together.

\section{Parental status}

Some fertility treatment centers only assist with posthumous reproduction to produce a sibling in cases where the couple already had a child [19]. The motivation to produce a sibling for an only child may be rooted in long-standing negative stereotypes about the personality of only children, who have been labeled as spoiled and overindulged for over a century $[20,21]$. However, research has found few differences between only children and those with siblings, and where differences do exist they often favor only children [22]. Moreover, if the couple has already produced offspring then it seems reasonable to argue that the procreative desires [23] of the couple have been sufficiently satiated. Conversely, unfulfilled procreative desires may provide a compelling rationale in favor of posthumous reproduction for those who had not yet produced a child.

\section{Wishes of the deceased's parents}

The Revised Uniform Anatomical Gift Act [24] provides the legal framework for determining who can request posthumous gamete retrieval and donation [3]. The RUAGA stipulates that a spouse has decision-making priority before a parent and that a parent has decision-making authority before an unmarried cohabiting partner of the deceased unless, according to Section 9 (a) (1), the parent or intimate partner is acting as "an agent of the decedent at the time of death." Thus, in most cases a widow has sufficient legal status under the RUAGA to request posthumous sperm retrieval. Alternatively, if the deceased was not married and his parents hold decision-making authority then they have sufficient legal status under the RUAGA to block a retrieval request by an intimate partner.

In any case, however, physicians are not compelled to perform any medical procedure except in cases of emergency [25], so those opposed to the procedure for any reason may refuse a retrieval request even if made by a spouse or parent with sufficient legal status. A request for posthumous sperm retrieval may or may not be defined as an emergency; the request necessitates immediate attention because, according to the Cornell guidelines, sperm are only fully viable for about 3 hours postmortem then progressively degrade until they become unviable roughly 24 hours postmortem, but the situation is not life-threatening. Thus, posthumous sperm retrieval is a unique situation in which the requested medical procedure must be performed immediately to succeed but can justly be argued does not constitute a bona fide emergency. 
Given the latitude for physicians to exercise judgment in these cases, one factor that may sway a physician experiencing ambivalence concerning a widow's request for posthumous sperm retrieval is whether the wishes of the deceased's parents are concordant with those of the widow. In fact, the Cornell guidelines indicate that, although the wife should be the one who makes a decision about postmortem sperm retrieval, conflict among interested parties is a contraindication to the procedure.

Although cases have arisen where parents requested posthumous sperm retrieval from a deceased unmarried child to provide the possibility for a biological grandchild [26-28], cases have also occurred where the deceased's parents have not been supportive of a spouse's retrieval request. In one such case, the widow of a soldier obtained a court ruling allowing the deceased's sperm to be retrieved over the objections of his mother, who had control of the remains [29]. Another mother sought legal intervention to prevent conception using her deceased son's cryopreserved sperm, which he had stored prior to beginning chemotherapy treatments and later donated to his girlfriend [30]. In yet another family, a soldier had cryopreserved his sperm prior to deployment so his wife could continue attempting to conceive in his absence. Conception had not yet occurred when he died but was still desired by his wife; the soldier's parents were initially not supportive, but later embraced the wife's decision [31].

\section{Context of death}

The Cornell guidelines stipulate that sperm should only be retrieved posthumously if the death occurred unexpectedly. Although not stated, this requirement is presumably based on an assumption that the deceased would have cryopreserved his sperm himself if death was known to be imminent and he consented to posthumous conception. The argument is logical, but Hans [3] did not find any meaningful differences in attitudes toward posthumous gamete retrieval according to whether a death was anticipated (cancer) or sudden (car accident).

In addition to whether the death could have been anticipated, cause is another dimension of death that may affect attitudes toward posthumous sperm retrieval. If one is culpable in his own death, as in the case of suicide or other reckless behavior, then public sentiment for the deceased and his desire to produce offspring may be muted. Examples of cases where the deceased was to some degree culpable in his own death include two mothers of unmarried young adult sons who requested postmortem sperm retrieval following deaths attributed to fighting [26] and Russian roulette [32]; technically, this wasn't a case of postmortem sperm retrieval because the young man was still on life support when the sperm was retrieved). In the latter case the mother indicated that she was doing what her son wanted, and in the former case the mother indicated that this was her only chance to have a grandchild, suggesting both altruistic and egocentric motivations for posthumous reproduction.

In contrast to cases where the deceased is responsible in his own death, a great deal of latitude may be afforded to those who die in heroic fashion, such as a police officer who dies in the line of duty. Doucettperry [33], a U.S. Army judge, has argued that posthumous reproduction among service members should be limited to those who cryopreserve their sperm prior to death and some American and British soldiers cryopreserved their sperm as an insurance policy against infertility or death prior to deploying to Afghanistan or Iraq [34-38]. Moreover, at least one cryopreservation company offered a discount for members of the military who were deploying [39]. However, most soldiers do not cryopreserve their sperm prior to deployment, and cases have arisen where widows of soldiers have requested postmortem sperm retrieval to preserve the possibility of producing genetic offspring with their deceased husbands after some time has passed following the death [29].

Focusing on the context of death, whether the deceased was heroic or culpable, seems to presume that posthumous reproduction memorializes the deceased by creating what a French court termed a baby souvenir [40-42]. There is no doubt some degree of memorializing associated with posthumous reproduction, similar to the sense of legacy that having a child provides living parents. However, a strong argument could be made that posthumous reproduction has a more profound effect on the deceased's survivors and the resulting offspring than it does on the deceased's legacy.

\section{Wishes of deceased}

The deceased's wishes are the strongest predictor of attitudes toward posthumous gamete retrieval and beliefs concerning the degree of obligation medical professionals have to assist with a request for postmortem gamete retrieval [3]. The caveat is that the deceased's wishes are often unknown and cannot be directly obtained; interested parties are left to speculate about what the deceased may have wanted.

Procreation is viewed as a fundamental legal right by the U.S Supreme Court $[43,44]$, although the application of that right to posthumous reproduction is unclear [45]. The United Kingdom's Human Fertilization and Embryology Act of 1990 requires express written consent from the deceased for posthumous sperm retrieval [46]. Bennett [47] and Schiff [48] took that position by contending that even dying in the act of attempting to conceive is not sufficient evidence to infer the deceased's wishes to conceive posthumously because posthumous parenthood does not provide the experiences that make parenthood meaningful while living [49]. The stringency of a written consent standard, however, would preclude nearly all cases of postmortem sperm retrieval, particularly in cases of unexpected death, because adults of reproductive age rarely plan for death [50,51]. Consequently, others [52] have argued that the procedure could also be appropriate when there is compelling evidence to suggest that the deceased would have consented, if given the opportunity.

The Cornell guidelines take this more tolerant position by providing that a man's behaviors and statements prior to death indicating a clear intent to have offspring should be sufficient to warrant a widow's request for postmortem sperm retrieval. Others have gone further by suggesting that childbirth is so common in marriage that marriage itself can be construed as intent to procreate [53], and the United States has generally taken a laissez-faire approach to regulating postmortem gamete retrieval. The Ethics Committee for the American Society for Reproductive Medicine [54] recommends but does not require explicit consent of the deceased and states that there is no ethical duty to honor a retrieval request but that context and professional judgment should be used on a case by case basis.

Although there is little debate in the United States concerning the acceptability of posthumous gamete retrieval and conception, particularly when the deceased provided clear instructions, legislation has been developed to place practical limitations on claims against the deceased's estate. For example, the Uniform Parentage Act [55] limits paternity to offspring born within 300 days of a father's death, unless the deceased otherwise consented in writing. The Uniform Probate Code [56] was amended in 2008 to address posthumously conceived children and treats a child as living at the time of a parent's death for probate purposes if (a) the deceased consented to posthumous 
conception in writing, (b) the child is in utero within 36 months or is born within 45 months of the deceased's death, and (c) the child lives 120 hours after birth. Thus, although the absence of explicit consent does not preclude postmortem sperm retrieval in the United States, having explicit consent does afford legal status to resulting offspring.

\section{Method}

\section{Sample}

Respondents were contacted using a modified, list-assisted Waksberg [57] random-digit dialing method giving every household telephone in the continental United States an equal probability of being contacted. To reduce within-unit sampling bias, the respondent within each household was randomly selected according to the youngest or oldest adult of a given sex living in the household. Up to 15 call attempts were made to each telephone number in the sample, and a conversion attempt was made for each initial refusal.

These procedures resulted in a sample of 846 respondents, ranging in age from 18 to 95 years $(M=50, S D=16)$. The majority of respondents were female $(62 \%)$, married $(63 \%)$, White $(82 \%)$, and had children (76\%). Level of formal education was diverse: $20 \%$ had a post-bachelor's degree, $24 \%$ had a bachelor's degree, $33 \%$ had completed some college but did not have a degree, 19\% had a high school diploma, and 5\% had less than a high school diploma. Roughly $11 \%$ reported ever being widowed. Relative to the U.S. population from which this sample was drawn, Whites, females, college educated, and married individuals were overrepresented $[58,59]$. The distribution of religious affiliation was generally consistent with the U.S. population as reported by the Pew Forum on Religion and Public Life [60]; the most commonly reported religious affiliations were Protestant (54\%) and Catholic (27\%). Overall, $38 \%$ indicated that they were very religious, $35 \%$ classified themselves as somewhat religious, $13 \%$ were slightly religious, and $15 \%$ were not religious.

\section{Design and procedure}

Multiple Segment Factorial Vignettes (MSFVs) combine the random manipulation of variables in factorial designs and the contextual richness of multiple segment vignettes [61]. The threesegment vignette designed for this study described a fictional situation where a surviving wife or cohabiting girlfriend wished to have the sperm of her deceased partner posthumously retrieved to conceive a child. Respondents were randomly presented one of 48 versions of the vignette, which varied by manipulation of five independent design variables that were embedded within the vignette: (a) marital status, (b) parental status, (c) wishes of the deceased's parents, (d) context of death, and (e) wishes of the deceased.

In the first segment, respondents were told about a couple who had either been cohabitating or married for several years and who either did or did not already have a child when the husband suddenly died. Following his death, the wife requested that her partner's sperm be retrieved and cryopreserved so she could potentially have a/another child with him. As an example, the version that portrayed the couple as married and not having a child together was presented as follows (independent variables are italicized):

Robert and Angela have been happily married for several years. They did not have a child together but were planning to eventually have a child when Robert suddenly died. Following his death, Angela asked doctors to freeze Robert's sperm so she could potentially have a biological child with Robert after some time has passed following his death (Segment 1 example).
Respondents were then asked: (a) "Do you think Angela should or should not be able to have her deceased husband/partner's sperm frozen?" and (b) "For this procedure to be successful, the sperm would have to be frozen within 24 hours of Robert's death. Given the time-sensitive nature of this procedure, how obligated are medical professionals to follow Angela's wishes; would you say highly obligated, moderately obligated, slightly obligated, or not at all obligated?" Then, respondents were instructed, "Briefly explain in your own words why you chose these answers," and their responses were typed verbatim.

In the next vignette segment, which continued the hypothetical story from the first segment, the deceased partner's parents were depicted as being either supportive or unsupportive of the request to cryopreserve their son's sperm. In the following example, the deceased's parents were unsupportive of the decision:

During a family consultation to discuss the requested procedure, the medical professional learns that Robert's parents are unsupportive of Angela's desire to freeze his sperm (Segment 2 example).

After hearing the second segment, respondents were asked: (a) "Given this new information, do you think Angela should or should not be able to have her deceased husband/partner's sperm frozen?" and (b) "Keeping in mind the time-sensitive nature of this procedure, how obligated are medical professionals to follow Angela's wishes; would you say highly obligated, moderately obligated, somewhat obligated, or not at all obligated?" Once again, respondents were also asked to provide a rationale for their answers.

The third segment of the vignette revealed the final two independent variables: context of death and wishes of the deceased. The context of death was depicted as either a soldier who had died in combat or a thrill seeker who had died in a bungee-jumping accident. Respondents were also told that the couple had previously discussed the risks involved with either military deployment or thrill-seeking adventures and that the deceased had agreed in writing, agreed orally, or had not discussed the possibility of posthumous reproduction if he were to experience an untimely death. The following example depicts Robert as a soldier and indicates that he and Angela had not discussed the possibility of posthumous reproduction in the event of his death:

It turns out that Robert was a soldier and died in combat. The couple had discussed the risks involved in Robert's deployment, but they had not discussed the possibility of having his sperm frozen to have a child after his death if something were to happen to him (Segment 3 example).

The same two questions that were asked following the second segment were then repeated, followed by the request to provide a rationale for those responses.

\section{Analytic approach}

Logistic regression models were created for each of the three questions that asked whether postmortem sperm retrieval should or should not be allowed, and ordinal regression models were created for each of the three questions about medical professionals' obligation to assist. In all six regression models, the main effects of the independent design variables were forced into the models, then a planned interaction (i.e., marital status $\mathrm{x}$ parents' wishes) was entered using a stepwise procedure, and in the final entry block respondent characteristics were forced into the models.

The rationales respondents provided for their responses to the closed-ended questions were typed verbatim and coded inductively. 
The coding unit was a unique rationale, so a single response may have been coded into multiple categories. Approximately one-third of the responses were coded by a second coder to test for inter-rater reliability, which resulted in a substantial amount of agreement $(\mathrm{kappa}=0.76)$ between the two coders [62]

\section{Results}

\section{Should posthumous gamete retrieval be allowed?}

Overall, the majority of respondents indicated that the request for posthumous sperm retrieval should be allowed regardless of which versions of the independent variables they were presented (Table 1). However, responses were consistently affected across vignette segments by several independent variables and respondent religiosity. Specifically, respondents who heard about a cohabiting couple and those who heard that the deceased's parents were unsupportive were about half as likely to say that the procedure should be allowed compared to those who heard about a married couple and those who heard about supportive parents, respectively. The strongest predictor of responses, however, was the deceased's wishes; respondents were over 2.5 times more likely to indicate that the sperm should be retrieved if they heard that the deceased had concurred with the procedure, either orally or in writing, prior to death than if they heard that the couple had not discussed the possibility of posthumous reproduction. Religiosity was the only respondent characteristic that was statistically related to the responses; the more closely respondents identified with their religious affiliation the less likely they were to indicate that posthumous sperm retrieval should be allowed. Complete statistical results for the logistic regression analyses are presented in Table 2 .

\section{How obligated are medical professionals?}

Responses to the items asking how obligated medical professionals were to assist with the posthumous sperm retrieval request were distributed consistently across vignette segments; among those who had an opinion, roughly $40 \%$ of respondents selected highly obligated, $20 \%$ said moderately obligated, $10 \%$ chose slightly obligated, and $30 \%$ said not at all obligated. However, the descriptive statistics depicted in Table 3 suggest that responses varied according to some of the independent variables. Specifically, responses varied in consistent and predictable ways according to the marital status, wishes of the deceased's parents,

\begin{tabular}{lcccc}
\hline & \multicolumn{5}{l}{ Should or should not be allowed? } \\
\cline { 2 - 5 } Independent variable & $n$ & Should not & Should & Don't know \\
\hline Marital status & 434 & 43.5 & 51.4 & 5.1 \\
Cohabitating & 407 & 29.7 & 66.8 & 3.4 \\
Married & & & & \\
Parental status & 415 & 36.4 & 59.8 & 3.9 \\
No children & 426 & 37.3 & 58.0 & 4.7 \\
Had children & & & & \\
Wishes of deceased's parents & 409 & 42.3 & 51.1 & 6.6 \\
Not in favor & 430 & 25.8 & 71.2 & 3.0 \\
Supportive & & & & \\
Cause of death & 414 & 27.5 & 68.8 & 3.6 \\
Soldier & 426 & 30.0 & 66.2 & 3.8 \\
Thrill seeker & & & & \\
Wishes of deceased & 302 & 39.7 & 55.0 & 5.3 \\
Unknown & 270 & 23.3 & 74.4 & 2.2 \\
Verbal & 268 & 22.0 & 74.6 & 3.4 \\
Written &
\end{tabular}

Table 1: Percentage of Responses within Each Level of the Independent Variables. and deceased's wishes depicted in the vignette, and respondents who more closely identified with their religious affiliation tended to intuit less obligation to assist on the part of medical professionals. Beliefs about the degree of obligation on the part of medical professionals to assist with the requested procedure did not statistically vary according to the parental status or context of death depicted in the vignette. Also, although these respondents attributed more obligation if they heard that the deceased's wishes had been in writing than if they heard that the wishes had been stated verbally, the size of that difference was too small to make a statistical distinction with these data. Complete statistical results for the ordinal regression analyses are presented in Table 4.

\section{Rationale for responses}

The most frequent rationales provided for responses to the closedended questions are summarized in Table 5. The results substantiate the quantitative results in that many respondents referenced the couple's marital status, the opinion of the deceased's parents, and the deceased's wishes when explaining their responses. Moreover, only one respondent referenced parental status by suggesting that the procedure should be allowed to provide a sibling for an existing child, and no rationales were provided referencing the context of death that had been portrayed in the vignette.

Although the relative frequency of rationales that referenced the independent variables were generally in the expected directions according to the statistical results described above, responses were more nuanced with regard to the opinion of the deceased's parents. Respondents who stated that posthumous sperm retrieval should not be allowed rarely cited the lack of parental support as justification for that position, regardless of whether the couple was depicted as married or cohabiting. These respondents seemed to view unsupportive parents as merely substantiating an already entrenched position. Perhaps for similar reasons, respondents who remained opposed to the requested procedure after hearing that the deceased's parents were supportive often dismissed the parents' position as unimportant, and those who heard about a cohabiting couple $(24 \%)$ were more likely to do so than those who heard about a married couple (12\%).

Compared to those who were opposed to retrieval of the sperm, respondents in favor of retrieval were much more likely to cite the parents' position in their rationales. Those who heard about supportive parents frequently stated that the parents' opinion is important regardless of whether they heard about a cohabiting $(37 \%)$ or a married (50\%) couple, and those who heard about unsupportive parents frequently stated that the parents' opinion was unimportant regardless of whether they heard about a cohabiting (33\%) or married (24\%) couple. In short, these response patterns indicate that many respondents downplayed the parents' opinion if it was discordant with their own pre-existing or otherwise-determined position, or the parents' opinion tended to be absent from the rationale in cases where both the respondent and the parents were opposed to retrieval.

In addition to the independent variables, many who believed posthumous sperm retrieval should be allowed indicated that it was the surviving partner's decision to make, and others intuited that there was an agreement between the couple in the first and second segments even before any history of a discussion between the couple was revealed in the third segment. Those who indicated that posthumous retrieval should not be allowed were more varied in the rationales they provided; many believed the surviving partner should move on with her life rather than try to have a child with the deceased partner, concern was expressed for 
Citation: Hans JD, Yelland EL (2013) American Attitudes in Context: Posthumous Sperm Retrieval and Reproduction. J Clinic Res Bioeth S1: 008. doi:10.4172/2155-9627.S1-008

Page 6 of 9

\begin{tabular}{|c|c|c|c|c|c|c|c|c|c|c|c|c|c|c|c|}
\hline \multirow[b]{2}{*}{ Predictor } & \multicolumn{5}{|c|}{$\begin{array}{l}\text { Segment } 1 \\
n=745, \text { should }=62 \%\end{array}$} & \multicolumn{5}{|c|}{$\begin{array}{l}\text { Segment } 2 \\
n=723, \text { should }=65 \%\end{array}$} & \multicolumn{5}{|c|}{$\begin{array}{l}\text { Segment } 3 \\
n=725, \text { should }=70 \%\end{array}$} \\
\hline & $B$ & $S E$ & $p$ & OR & $95 \% \mathrm{Cl}$ & $B$ & SE & $p$ & OR & $95 \% \mathrm{Cl}$ & $B$ & $S E$ & $p$ & OR & $95 \% \mathrm{Cl}$ \\
\hline Unmarried (married) & -0.67 & .16 & $<.001$ & 0.51 & $\begin{array}{l}{[0.38} \\
0.70]\end{array}$ & -0.74 & .17 & $<.001$ & 0.48 & {$[0.35,0.66]$} & -0.96 & .18 & $<.001$ & 0.38 & {$[0.27,0.54]$} \\
\hline No children (had children) & 0.06 & .16 & .725 & 1.06 & $\begin{array}{l}{[0.78} \\
1.44]\end{array}$ & 0.00 & .17 & .987 & 1.00 & {$[0.73,1.39]$} & -0.09 & .18 & .614 & 0.92 & {$[0.65,1.29]$} \\
\hline Parents' unsupportive (supportive) & & & & & & -0.85 & .17 & $<.001$ & 0.43 & {$[0.31,0.59]$} & -0.50 & .18 & .004 & 0.61 & {$[0.43,0.85]$} \\
\hline Soldier died in combat (died bungee-jumping) & & & & & & & & & & & 0.04 & .18 & .822 & 1.04 & {$[0.74,1.47]$} \\
\hline $\begin{array}{l}\text { Deceased's wishes unknown (verbal } \\
\text { consent) }\end{array}$ & & & & & & & & & & & -0.89 & .21 & $<.001$ & 0.41 & {$[0.27,0.63]$} \\
\hline $\begin{array}{l}\text { Deceased's wishes unknown (written } \\
\text { consent) }\end{array}$ & & & & & & & & & & & -0.86 & .21 & $<.001$ & 0.42 & {$[0.28,0.64]$} \\
\hline $\begin{array}{l}\text { Deceased consented verbally (written } \\
\text { consent) }\end{array}$ & & & & & & & & & & & -0.03 & .23 & .901 & 0.97 & {$[0.62,1.53]$} \\
\hline \multicolumn{16}{|l|}{ Respondent characteristics } \\
\hline Age & -0.00 & .01 & .784 & 1.00 & $\begin{array}{l}{[0.99} \\
1.01]\end{array}$ & 0.00 & .01 & .979 & 1.00 & {$[0.99,1.01]$} & -0.00 & .01 & .879 & 1.00 & {$[0.99,1.01]$} \\
\hline Education & -0.10 & .07 & .162 & 0.91 & $\begin{array}{l}{[0.79} \\
1.04]\end{array}$ & -0.07 & .07 & .339 & 0.93 & {$[0.81,1.08]$} & 0.01 & .08 & .893 & 1.01 & {$[0.87,1.18]$} \\
\hline Income & -0.14 & .07 & .037 & 0.87 & $\begin{array}{l}{[0.77} \\
0.99]\end{array}$ & -0.10 & .07 & .168 & 0.91 & {$[0.80,1.04]$} & -0.02 & .07 & .836 & 0.99 & {$[0.86,1.13]$} \\
\hline Male (female) & 0.15 & .17 & .353 & 1.17 & $\begin{array}{l}{[0.84} \\
1.61]\end{array}$ & -0.11 & .17 & .518 & 0.90 & {$[0.64,1.25]$} & -0.14 & .18 & .457 & 0.87 & {$[0.61,1.25]$} \\
\hline Never been married (has been married) & -0.02 & .31 & .938 & 0.98 & $\begin{array}{l}{[0.54} \\
1.78]\end{array}$ & 0.10 & .32 & .748 & 1.11 & {$[0.59,2.08]$} & 0.01 & .35 & .983 & 1.01 & {$[0.51,2.00]$} \\
\hline Never been widowed (has been widowed) & -0.37 & .28 & .179 & 0.69 & $\begin{array}{l}{[0.40} \\
1.18]\end{array}$ & -0.26 & .29 & .374 & 0.77 & {$[0.44,1.36]$} & 0.23 & .29 & .426 & 1.26 & {$[0.71,2.24]$} \\
\hline Never had children (has had children) & 0.35 & .24 & .146 & 1.42 & $\begin{array}{l}{[0.89} \\
2.28]\end{array}$ & 0.51 & .26 & .047 & 1.66 & {$[1.01,2.75]$} & 0.50 & .28 & .075 & 1.64 & {$[0.95,2.84]$} \\
\hline Religiosity & -0.23 & .09 & .007 & 0.79 & $\begin{array}{l}{[0.67} \\
0.94]\end{array}$ & -0.23 & .09 & .012 & 0.79 & {$[0.66,0.95]$} & -0.38 & .10 & $<.001$ & 0.69 & {$[0.56,0.84]$} \\
\hline \multicolumn{16}{|l|}{ Religion } \\
\hline Catholic (no preference) & -0.40 & .49 & .413 & 0.67 & $\begin{array}{l}{[0.26} \\
1.74]\end{array}$ & 0.27 & .46 & .563 & 1.31 & {$[0.53,3.24]$} & 0.45 & .50 & .368 & 1.57 & {$[0.59,4.15]$} \\
\hline Jewish (no preference) & 0.34 & .76 & .655 & 1.40 & $\begin{array}{l}{[0.32} \\
6.16]\end{array}$ & 0.95 & .82 & .247 & 2.58 & $\begin{array}{l}{[0.52} \\
12.77]\end{array}$ & 0.07 & .75 & .927 & 1.07 & {$[0.25,4.68]$} \\
\hline Protestant ${ }^{\text {(no preference) }}$ & -0.49 & .48 & .305 & 0.61 & $\begin{array}{l}{[0.24} \\
1.56]\end{array}$ & 0.13 & .45 & .770 & 1.14 & {$[0.47,2.76]$} & 0.32 & .49 & .510 & 1.38 & {$[0.53,3.56]$} \\
\hline
\end{tabular}

Note: Reference category in parentheses. $\mathrm{Cl}$ = confidence interval for odds ratio (OR)

Table 2: Logistic Regression Predicting Whether Retrieval of Deceased Husband's Gametes Should be Allowed.

\begin{tabular}{|c|c|c|c|c|c|c|}
\hline \multirow[b]{2}{*}{ Independent variable } & \multicolumn{6}{|c|}{ How obligated are medical professionals to assist? } \\
\hline & $n$ & Not at all & Slightly & Moderately & Highly & Don't know \\
\hline \multicolumn{7}{|l|}{ Marital status } \\
\hline Cohabitating & 434 & 39.4 & 9.2 & 18.9 & 28.3 & 4.1 \\
\hline Married & 406 & 22.2 & 11.3 & 20.2 & 42.4 & 3.9 \\
\hline \multicolumn{7}{|l|}{ Parental status } \\
\hline No children & 414 & 31.9 & 10.1 & 18.8 & 34.5 & 4.6 \\
\hline Had children & 426 & 30.3 & 10.3 & 20.2 & 35.7 & 3.5 \\
\hline \multicolumn{7}{|c|}{ Wishes of deceased's parents } \\
\hline Not in favor & 408 & 33.8 & 15.2 & 16.7 & 30.4 & 3.9 \\
\hline Supportive & 430 & 24.2 & 9.1 & 19.8 & 45.6 & 1.4 \\
\hline \multicolumn{7}{|l|}{ Cause of death } \\
\hline Soldier & 414 & 25.8 & 9.4 & 19.6 & 42.5 & 2.7 \\
\hline Thrill seeker & 426 & 26.1 & 9.6 & 17.4 & 44.1 & 2.8 \\
\hline \multicolumn{7}{|l|}{ Wishes of deceased } \\
\hline Unknown & 302 & 32.5 & 10.6 & 20.5 & 33.4 & 3.0 \\
\hline Verbal & 271 & 21.8 & 10.3 & 19.2 & 45.4 & 3.3 \\
\hline Written & 267 & 22.8 & 7.5 & 15.4 & 52.4 & 1.9 \\
\hline
\end{tabular}

Table 3: Percentage of Responses within Each Level of the Independent Variables.

the child who would be born without a father into a single-parent home, and others objected based on a belief that posthumous gamete retrieval and reproduction is in some way unethical, immoral, unnatural, or is a form of "playing God." 
Citation: Hans JD, Yelland EL (2013) American Attitudes in Context: Posthumous Sperm Retrieval and Reproduction. J Clinic Res Bioeth S1: 008. doi:10.4172/2155-9627.S1-008

Page 7 of 9

\begin{tabular}{|c|c|c|c|c|c|c|c|c|c|c|c|c|c|c|c|}
\hline \multirow[b]{2}{*}{ Predictor } & \multicolumn{5}{|c|}{$\begin{array}{l}\text { Segment } 1 \\
n=722\end{array}$} & \multicolumn{5}{|c|}{$\begin{array}{l}\text { Segment } 2 \\
n=729\end{array}$} & \multicolumn{5}{|c|}{$\begin{array}{l}\text { Segment } 3 \\
n=727\end{array}$} \\
\hline & $B$ & SE & $p$ & OR & $95 \% \mathrm{Cl}$ & $B$ & SE & $p$ & OR & $95 \% \mathrm{Cl}$ & $B$ & SE & $P$ & OR & $95 \% \mathrm{Cl}$ \\
\hline Unmarried (married) & -0.77 & .14 & $<.001$ & 0.46 & {$[0.35,0.61]$} & -0.70 & .14 & $<.001$ & 0.49 & $\begin{array}{l}{[0.38} \\
0.65]\end{array}$ & -0.69 & .14 & $<.001$ & 0.50 & {$[0.38,0.66]$} \\
\hline No children (had children) & -0.12 & .14 & .385 & 0.89 & {$[0.67,1.16]$} & -0.01 & .14 & .917 & 0.99 & $\begin{array}{l}{[0.75} \\
1.29]\end{array}$ & -0.06 & .14 & .682 & 0.94 & {$[0.71,1.25]$} \\
\hline Parents' unsupportive (supportive) & & & & & & -0.68 & .14 & $<.001$ & 0.51 & $\begin{array}{l}{[0.38} \\
0.67]\end{array}$ & -0.35 & .14 & .013 & 0.70 & {$[0.53,0.93]$} \\
\hline $\begin{array}{l}\text { Soldier died in combat (died bungee- } \\
\text { jumping) }\end{array}$ & & & & & & & & & & & -0.04 & .14 & .767 & 0.96 & {$[0.73,1.26]$} \\
\hline $\begin{array}{l}\text { Deceased's wishes unknown (verbal } \\
\text { consent) }\end{array}$ & & & & & & & & & & & -0.52 & .17 & .002 & 0.60 & {$[0.43,0.83]$} \\
\hline $\begin{array}{l}\text { Deceased's wishes unknown (written } \\
\text { consent) }\end{array}$ & & & & & & & & & & & -0.65 & .17 & $<.001$ & 0.52 & {$[0.37,0.74]$} \\
\hline $\begin{array}{l}\text { Deceased consented verbally } \\
\text { (written consent) }\end{array}$ & & & & & & & & & & & -0.13 & .18 & .476 & 0.88 & {$[0.62,1.25]$} \\
\hline \multicolumn{16}{|l|}{ Respondent characteristics } \\
\hline Age & -0.01 & .01 & .195 & 0.99 & {$[0.98,1.00]$} & 0.00 & .01 & .353 & 1.00 & $\begin{array}{l}{[0.98} \\
1.01]\end{array}$ & -0.01 & .01 & .081 & 0.99 & {$[0.98,1.00]$} \\
\hline Education & -0.14 & .06 & .028 & 0.87 & {$[0.77,0.99]$} & -0.11 & .06 & .070 & 0.89 & $\begin{array}{l}{[0.79} \\
1.01]\end{array}$ & -0.06 & .06 & .332 & 0.94 & {$[0.83,1.07]$} \\
\hline Income & -0.07 & .06 & .257 & 0.94 & {$[0.84,1.05]$} & -0.05 & .06 & .397 & 0.95 & $\begin{array}{l}{[0.85} \\
1.07]\end{array}$ & -0.01 & .06 & .892 & 0.99 & {$[0.88,1.11]$} \\
\hline Male (female) & -0.04 & .15 & .775 & 0.96 & {$[0.72,1.28]$} & -0.07 & .15 & .649 & 0.94 & $\begin{array}{l}{[0.70} \\
1.24]\end{array}$ & -0.04 & .15 & .777 & 0.96 & {$[0.72,1.28]$} \\
\hline Never been married (has been married) & -0.07 & .26 & .796 & 0.93 & {$[0.56,1.57]$} & -0.03 & .26 & .924 & 0.98 & $\begin{array}{l}{[0.58} \\
1.63]\end{array}$ & -0.07 & .27 & .806 & 0.94 & {$[0.55,1.59]$} \\
\hline Never been widowed (has been widowed) & -0.17 & .24 & .476 & 0.84 & {$[0.53,1.34]$} & -0.10 & .24 & .687 & 0.91 & $\begin{array}{l}{[0.57} \\
1.45]\end{array}$ & -0.13 & .24 & .596 & 0.88 & {$[0.55,1.41]$} \\
\hline Never had children (has had children) & 0.16 & .21 & .454 & 1.17 & {$[0.78,1.76]$} & 0.09 & .21 & .653 & 1.10 & $\begin{array}{l}{[0.73} \\
1.66]\end{array}$ & 0.20 & .21 & .358 & 1.22 & {$[0.80,1.85]$} \\
\hline Religiosity & -0.17 & .08 & .025 & 0.84 & {$[0.73,0.98]$} & -0.14 & .08 & .075 & 0.87 & $\begin{array}{l}{[0.75} \\
1.01]\end{array}$ & -0.15 & .08 & .054 & 0.86 & {$[0.74,1.00]$} \\
\hline \multicolumn{16}{|l|}{ Religion } \\
\hline Catholic (no preference) & 0.49 & .39 & .212 & 1.63 & {$[0.76,3.49]$} & -0.36 & .40 & .364 & 0.32 & $\begin{array}{l}{[0.32} \\
1.52]\end{array}$ & -0.38 & .41 & .351 & 0.68 & {$[0.30,1.53]$} \\
\hline Jewish (no preference) & 1.22 & .65 & .060 & 3.38 & {$[0.95,12.08]$} & 0.03 & .67 & .969 & 0.28 & $\begin{array}{l}{[0.28} \\
3.82]\end{array}$ & -0.50 & .65 & .437 & 0.60 & {$[0.17,2.15]$} \\
\hline Protestant ${ }^{\text {(no preference) }}$ & 0.31 & .38 & .411 & 1.37 & {$[0.65,2.89]$} & -0.52 & .39 & .180 & 0.28 & $\begin{array}{l}{[0.28} \\
1.27]\end{array}$ & -0.50 & .40 & .217 & 0.61 & {$[0.28,1.34]$} \\
\hline
\end{tabular}

Note: Reference category in parentheses. $\mathrm{Cl}=$ confidence interval for odds ratio $(O R)$

Table 4: Ordinal Regression Predicting How Obligated Medical Professionals are to Follow Widow's Wishes to Retrieve Deceased Husband's Gametes.

\begin{tabular}{|c|c|c|c|c|c|c|}
\hline \multirow[b]{2}{*}{ Rationale } & \multicolumn{2}{|c|}{ Segment 1} & \multicolumn{2}{|c|}{ Segment 2} & \multicolumn{2}{|c|}{ Segment 3} \\
\hline & $n$ & $\%$ & $n$ & $\%$ & $n$ & $\%$ \\
\hline Should & 485 & & 496 & & 546 & \\
\hline Survivor's wishes or rights & 125 & 25.8 & 111 & 22.4 & 106 & 19.4 \\
\hline Couple agreement & 72 & 14.8 & 41 & 8.3 & 117 & 21.4 \\
\hline Married couple & 51 & 10.5 & 58 & 11.7 & 23 & 4.2 \\
\hline Parents' opinion irrelevant & & & 103 & 20.8 & 18 & 3.3 \\
\hline Parents' opinion important & & & 89 & 17.9 & 35 & 6.4 \\
\hline Had documentation & & & & & 65 & 11.9 \\
\hline Deceased's wishes & & & & & 56 & 10.3 \\
\hline Should not & 302 & & 270 & & 235 & \\
\hline Not married & 74 & 27.4 & 65 & 24.1 & 45 & 19.1 \\
\hline Deceased's wishes unknown & 67 & 24.8 & 38 & 14.1 & 52 & 22.1 \\
\hline Move on with life & 39 & 14.4 & 23 & 8.5 & 28 & 11.9 \\
\hline Concerns for child & 35 & 13.0 & 30 & 11.1 & 32 & 13.6 \\
\hline Unnatural or religion & 29 & 10.7 & 19 & 7.0 & 23 & 9.8 \\
\hline Lacking documentation & 23 & 8.5 & 15 & 5.6 & 18 & 7.7 \\
\hline Ethical or moral concern & 20 & 7.4 & 17 & 6.3 & 17 & 7.2 \\
\hline Parents' opinion important & & & 33 & 12.2 & 12 & 5.1 \\
\hline Parents' opinion irrelevant & & & 18 & 6.7 & 0 & 0.0 \\
\hline
\end{tabular}

Table 5: Most common Rationale for whether Posthumous Conception Should or Should Not be Allowed. 
Citation: Hans JD, Yelland EL (2013) American Attitudes in Context: Posthumous Sperm Retrieval and Reproduction. J Clinic Res Bioeth S1: 008. doi:10.4172/2155-9627.S1-008

\section{Discussion}

The purpose of this study was to examine the effects of contextual circumstances on attitudes toward posthumous retrieval of sperm for the purpose of cryopreservation and subsequent reproduction. Results consistently indicated that marital status, disposition of the deceased's parents, and the deceased's wishes affected attitudes in the expected directions, that parental status and cause of death had little bearing on attitudes, and that respondent religiosity was negatively correlated with the perceived acceptability of posthumous sperm retrieval. In addition, the perceived obligation of medical professionals to assist with a posthumous sperm retrieval request was closely aligned with the perceived acceptability of the procedure itself.

Despite subtle vignette differences, the directions and magnitudes of these findings are generally consistent with those obtained by Hans [3] using a probability sample of Kentucky residents. However, there were three notable differences in our results: (a) odds ratios associated with the deceased's wishes were notably smaller, (b) the deceased's verbal consent to the procedure carried more weight relative to written consent; the two were indistinguishable in our sample, and (c) respondent education was not associated with attitudes toward the procedure. These differences notwithstanding, the largely consistent findings between the two studies provide an added degree of confidence in our findings.

These findings, buttressed by their consistency with those of Hans [3], may be taken as tentative estimates of public opinion on posthumous reproduction and could therefore rightfully influence policy and medical decision-making. However, attempts to apply these findings should be tempered by a few key limitations of these data.

Posthumous sperm retrieval and posthumous conception are increasing in prevalence yet remain sufficiently rare to assume that the vast majority of the population has never encountered these situations within their social networks. The complexities of the issues inherent in posthumous reproduction challenge bioethics panels who carefully consider the various interests at stake, yet we asked respondents to make on-the-spot decisions on issues for which they did not hold informed or thoughtful positions. First-impression responses have some merit in the sense that the positions taken are not directly influenced by politics and media pundits, and the sentiments expressed in these data may therefore reflect core values, but some people may arrive at different or more nuanced positions with further and fuller consideration of the issues at hand and interests at stake with regard to posthumous reproduction.

Also, we asked what the characters in the vignettes should do, not what our respondents would do, in the given situation. Although the theory of planned behavior [63] suggests that attitudes and behaviors are related to one another, we caution against assuming that responses to these hypothetical vignette situations reflect the decisions individuals would make, or the wishes they would hold for themselves, if faced with the same situation in their own lives. Emotional distance and the absence of real-world consequences and context allow respondents to make judgments in response to vignettes that may only vaguely resemble the decision-making process one makes when fully immersed in a real-world context. For example, Carlson [64] found a disconnect between what respondents stated should happen in response to vignettes depicting violent and abusive incidents in relationships and what people who experience violence and abuse in their relationships actually do. Similarly, relative to actual reported behavior, the results of a vignette study on needle sharing among drug injectors demonstrated a willingness to "flirt with risky behavior at no personal cost" in response to vignette scenarios [65].

With these limitations in mind, the multiple segment factorial vignette design employed in this study is nonetheless appropriate for understanding how various contextual circumstances affect attitudes relative to one another. Our findings provide evidence that can appropriately be weighed in the decision-making process when a posthumous retrieval request is made and, more generally, when policies are formed that delineate acceptable contextual circumstances for this procedure.

\section{Conclusion}

Medical advances enhance and extend life while simultaneously challenging existing notions about the meaning and boundaries of life, and few issues do so as provocatively as posthumous sperm retrieval and reproduction. The numerous quagmires introduced by posthumous reproduction thus far have been primarily examined with philosophical arguments and legalistic commentary. This study expands that conversation by providing the first national survey data in the United States focused on examining the perceived acceptability of posthumous sperm retrieval in various contexts among the general population. Overall, the findings indicate that most Americans are supportive of posthumous sperm retrieval and cryopreservation for reproductive purposes, particularly when circumstances are deemed favorable. Future research should build upon these findings by examining more varied contexts than was possible with the one vignette we employed. In addition, the scope of investigation should expand to take advantage of the fertile opportunities posthumous reproduction presents for exploring the meaning and role of reproduction, offspring, and parenting in modern life.

\section{References}

1. Ohl DA, Park J, Cohen C, Goodman K, Menge, AC (1996) Procreation after death or mental incompetence: Medical advance or technology gone awry? Fertility and Sterility 66: 889-895

2. Strong C, Gingrich JR, Kutteh WH (2000) Ethics of postmortem sperm retrieval: ethics of sperm retrieval after death or persistent vegetative state. Hum Reprod 15: 739-745.

3. Hans JD (2008) Attitudes toward posthumous harvesting and reproduction Death Stud 32: 837-869.

4. Rothman CM (1980) A method for obtaining viable sperm in the postmortem state. Fertil Steril 34: 512

5. Cohen P, Day M (1999) Never say die: you don't need to make sperm or even be alive to be a father. New Sci 161: 5 .

6. Bahadur G (2004) Ethical challenges in reproductive medicine: Posthumous reproduction. International Congress Series 1266: 295-302.

7. New York Hospital Guidelines for Consideration of Requests for Post-mortem Sperm Retrieval.

8. Tash JA, Applegarth LD, Kerr SM, Fins JJ, Rosenwaks Z, et al. (2003) Postmortem sperm retrieval: the effect of instituting guidelines. J Urol 170: 1922-1925.

9. Mizukami A, Peterson CM, Huang I, Cook C, Boyack LM, et al. (2005) The acceptability of posthumous human ovarian tissue donation in Utah. Hum Reprod 20: 3560-3565

10. Nakhuda GS, Wang JG, Sauer MV (2011) Posthumous assisted reproduction: a survey of attitudes of couples seeking fertility treatment and the degree of agreement between intimate partners. Fertil Steril 96: 1463-1466.

11. Hans JD (2013) Posthumous gamete retrieval and reproduction: American attitudes and the presumption against consent. Manuscript submitted for publication.

12. Kerr SM, Caplan A, Polin G, Smugar S, O'Neill K, et al. (1997) Postmortem sperm procurement. J Urol 157: 2154-2158. 
Citation: Hans JD, Yelland EL (2013) American Attitudes in Context: Posthumous Sperm Retrieval and Reproduction. J Clinic Res Bioeth S1: 008. doi:10.4172/2155-9627.S1-008

13. Hecht v. Superior Court, 20 Cal. Rptr. 2d 275 (Ct. App. 1993)

14. Cohn D, Passel JS, Wang W, Livingston G (2011) Barely half of U.S. adults are married - a record low. Washington, DC: Pew Research Center.

15. U.S. Census Bureau, Current Population Survey (2011) Table UC-1: Unmarried partners of the opposite sex, by presence of children: 1960 to present.

16. U.S. Census Bureau, Current Population Survey (2011) Table C-3: Living arrangements of children under 18 years.

17. Centers for Disease Control and Prevention (2006) National Center for Health Statistics (2006-2010) National Survey of Family Growth.

18. National Center for Health Statistics, Centers for Disease Control and Prevention, U.S. Department of Health and Human Services (2005). Fertility, family planning, and reproductive health of U.S women: Data from the 2002 National Survey of Family Growth (Vital and Health Statistics, Series 23, No. 25).

19. Corrigan E, Mumford SE, Hull MG (1996) Posthumous storage and use of sperm and embryos: survey of opinion of treatment centres. BMJ 313: 24 .

20. Adler A (1929/2005) Problems of neurosis. In HT Stein (Ed.), The collected works of Alfred Adler (Vol. 9, pp. 1-111). Bellingham, WA: Classical Adlerian Translation Project.

21. Bohannon, EW (1896) A study of peculiar and exceptional children. In GS Hall (Ed.), The pedagogical seminary (Vol. IV, pp. 3-60). Worcester, MA: J. H. Orpha.

22. Polit, DF, \& Falbo T (1987) Only children and personality development: A quantitative review. Journal of Marriage and the Family 49: 309-325.

23. Parker M (2004) Response to Orr and Siegler--collective intentionality and procreative desires: the permissible view on consent to posthumous conception. J Med Ethics 30: 389-392.

24. Paul A. Byrne, (2009) Revised Uniform Anatomical Gift Act.

25. Reiter J, Runyan C (2013) The ethics of complex relationships in primary care behavioral health. Fam Syst Health 31: 20-27.

26. Associated Press (2009) Grieving mother has dead son's sperm harvested.

27. Conley M (2011) Israeli court allows family to harvest dead daughter's eggs.

28. Dwyer LA (2000) Dead daddies: issues in postmortem reproduction. Rutgers Law Rev 52: 881-910.

29. Browne C. Lewis (2008) DEAD MEN REPRODUCING: RESPONDING TO THE EXISTENCE OF AFTERDEATH CHILDREN, Dhanoolal, United States Department of the Army, No. 4:08-CV-42.

30. Hall v. Fertility Institute of New Orleans (1994).

31. Oppenheim K (2007) Soldier fathers child two years after dying in Iraq.

32. Laurance J (1998) Mother wants to bear child from dead son's sperm. The Independent.

33. Doucettperry M (2008) To be continued: A look a posthumous reproduction as it relates to today's military. The Army Lawyer 1-22.

34. Alvord V (2003) Some troops freeze sperm before deploying.

35. Alvord V (2003) Troops start trend with sperm banks.

36. Buckley $F$ (2003) Insurance policy: Troops freezing sperm.

37. McDougall $L$ (2003) Soldiers preserve sperm as fear of new Gulf war grows.

38. Wheeler V (2011) Soldiers in sperm bank bid for wives. The Sun.

39. California Cryobank (CCB) offers special service for military (2003, January) California Cryobank.
40. Aziza-Shuster E (1994) A child at all costs: posthumous reproduction and the meaning of parenthood. Hum Reprod 9: 2182-2185.

41. Braun M, Baider L (2007) Souvenir children: death and rebirth. J Clin Onco 25: 5525-5527.

42. Landau R (1999) Planned orphanhood. Soc Sci Med 49: 185-196.

43. Gibbons JA (1997) Who's your daddy?: a constitutional analysis of postmortem insemination. J Contemp Health Law Policy 14: 187-210.

44. Skinner v. Oklahoma (1942) 316 U.S. 535

45. Antall KL (1999) Who is my mother?: why states should ban posthumous reproduction by women. Health Matrix Clevel 9: 203-234

46. McLean S (1997) Consent and the law: review of the current provisions in the Human Fertilisation and Embryology Act 1990 for the UK Health Ministers. Hum Reprod Update 3: 593-621.

47. Bennett B (1999) Posthumous reproduction and the meanings of autonomy. Melb Univ Law Rev 23: 286-307.

48. Schiff AR (1999) Posthumous conception and the need for consent. Med $J$ Aust 170: 53-54

49. Robertson JA (1994) Posthumous reproduction. Indiana Law J 69: 1027-1065

50. Leming MR, Dickinson GE (2011) Understanding dying, death, \& bereavement (7thedn), Belmont, CA: Wadsworth

51. Stillion J (1995) Death in the lives of adults: Responding to the tolling of bell. In $H$. Wass and R. Neimeyer, Dying: Facing the facts.

52. Strong C (1999) Consent to sperm retrieval and insemination after death or persistent vegetative state. J Law Health 14: 243-269.

53. Simpson B (2002) Making 'bad' deaths 'good': The kinship consequences of posthumous conception. Journal of the Royal Anthropological Institute 7: 1-18.

54. Ethics Committee of the American Society for Reproductive Medicine (2004) Posthumous reproduction. Fertility and Sterility.

55. Uniform Parentage Act (2002), 9B U.L.A.

56. Uniform Probate Code (2008) 8 U.L.A.

57. Waksberg J (1978) Sampling methods for random digit dialing. Journal of the American Statistical Association 73: 40-46.

58. U.S. Census Bureau. (2012). QuickFacts.

59. Census Bureau, Current Population Survey (2011) Table A1: Marital status of people 15 years and over, by age, sex, personal earnings, race, and Hispanic origin

60. Pew Forum on Religion \& Public Life (2008) Religious Landscape Survey Religious beliefs and practices. Diverse and politically relevant.

61. Ganong LH, Coleman M (2006) Multiple segment factorial designs. Journal of Marriage and Family 68: 455-468.

62. Landis JR, Koch GG (1977) The measurement of observer agreement for categorical data. Biometrics 33: 159-174.

63. Ajzen I (1991) The theory of planned behavior. Organizational Behavior and Human Decision Processes 50: 179-211.

64. Carlson BE (1996) Dating violence: Student beliefs about consequences Journal of Interpersonal Violence 11: 3-18.

65. McKeganey N, Abel M, Taylor A, Frischer M, Goldberg D, et al. (1995) The preparedness to share injecting equipment: an analysis using vignettes. Addiction 90: 1253-1260. 